\title{
A FAMÍLIA, A VISITA DOMICILIÁRIA E A ENFERMAGEM: REVISITANDO O PROCESSO DE TRABALHO DA ENFERMAGEM EM SAÚDE COLETIVA
}

\section{FAMILY, HOME VISITING AND NURSING: REVIEWING THE COLLECTIVE HEALTH NURSING LABOUR PROCESS}

EGRY, E.Y.; FONSECA, R.M.G.S. A família, a visita domiciliária e a enfermagem: revisitando o processo de trabalho da enfermagem em saúde coletiva. Rev.Esc.Enf.USP, v. 34, n.3, p. 233-9, set. 2000.

\section{RESUMO}

Tomando a família como Objeto de atenção da enfermagem em saúde coletiva, as autoras discutem as questões conceituais subjacentes ao objeto e à visita domiciliária, contextualizadas no conjunto da produção em saúde no Brasil, destacando-se o Programa de Atenção à Família e a Teoria de Intervenção Práxica da Enfermagem em Saúde Coletiva.

PALAVRAS-CHAVE: Enfermagem em Saúde Coletiva. Assistência a família. Cuidados domiciliares de Saúde. Família.

\begin{abstract}
The authors discuss the conceptualization of the therm family through sociohistorical transfomations of the societies. The finality of this study was to retake the discussion concerning home visiting as a health care instrument in Collective Health Nursing
\end{abstract}

KEYWORDS: Collective health nursing. Family care. Collective health nursing. Family.

\section{INTRODUÇÃO: a família em perspectiva}

O sistema de saúde engloba a produção dos serviços e as políticas de saúde, visando transformar os perfis de saúde-doença da população. Atualmente, no Brasil, a política de saúde vigente é norteada pelo Sistema Único de Saúde - SUS - que, regendo um dado modelo assistencial, oferta um conjunto de programas com estreita articulação entre si, objetivando contemplar os principios da Reforma Sanitária, quais sejam: regionalização, hierarquização, acessibilidade, eqüidade, participação e integralidade das ações. (BRASIL, 1990)
Para a implantação do SUS, as unidades de saúde organizam-se para a produção das ações, escolhendo meios e instrumentos eficazes para a intervenção nos perfis de saúde-doença da população pois, a depender dos modelos assistenciais vigentes, decorrentes das diretrizes emanadas das políticas públicas, diferentes instrumentos podem ser utilizados para essa intervenção.

Nos diferentes processos de trabalho, há uma certa tendência a tomar de forma assemelhada ou equivalente os Objetos' e os Instrumentos

\footnotetext{
Professora Titular do Departamento de Enfermagem em Saúde Coletiva da Escola de Enfermagem da Universidade de São Paulo.

10 objeto aqui referido é um dos elementos constitutivos do processo de trabalho, descrito por GONÇALVES, 1988. Demais elementos se referem, de acordo com o autor, à Finalidade e aos Meios/ Instrumentos. A articulação entre os três elementos constitutivos se realiza mergulhado no saber-ideológico que rege o processo de trabalho, ou seja, teleologicamente posto pelas políticas que regulam a produção em saúde de dada época e de dada sociedade. (EGRY et al, 1994)
} 
correspondentes, ocasionando equivocos e impedindo análises mais críticas e criteriosas para a consecução da Finalidade. Esta tendência aparece muito freqüentemente quando se trata da Visita Domiciliária e da Família pois, no primeiro caso trata-se de Instrumento e, no segundo, de Objeto do processo de trabalho, distinção nem sempre presente na literatura. Este ensaio pretende, além desta distinção, trazer à tona as possiblidades interventivas que o Instrumento comporta face ao Objeto considerado. Iniciemos, pois, entendendo os dois conceitos.

$O$ conceito de família (do latim famulus) tem se modificado de acordo com as transformações dos modos de produção social, havendo variâncias culturais dentro do mesmo modo de produção, na mesma época histórica, subjacentes às interferências dadas pelas diferentes culturas que compõem a formação social considerada. (ENGELS, 1984)

No Brasil, por exemplo, ainda hoje constatam-se diferentes valores e distintas formas de organização familiar em decorrência das raízes culturais de seus ancestrais, tais como entre os descendentes de italianos, japoneses, portugueses, judeus, etc, ou ainda distinções referentes à inserção rural ou urbana, além daquelas originadas pela diferenciação entre as classes sociais. (ALMEIDA, 1987)

Tais distinções, em termos da constituição e do significado dado às famílias, guardam relações com as transformações no modo de produção das sociedades ao longo dos tempos. No feudalismo, a terra, o principal meio de produção e a força produtiva do homem, resumindo-se à sua força física, determinavam relações de produção em que a geração de riqueza social dependia do trabalho dos servos, com a correspondente necessidade de se instituírem famílias numerosas e aglutinadas em torno da valorização da terra. O conceito de família englobava, então, não somente os parentes consangüíneos, mas também os servos, seus descendentes e todo o instrumental e animais necessários para o trabalho na terra. (ENGELS, 1984)

No capitalismo inicial, a valorização recaía sobre a indústria em instalação, principal sustentáculo do processo paralelo de urbanização. De acordo com as necessidades sociais da expansão da força de trabalho humana, agora voltadas para a produção de bens industrializados, as famílias, continuavam extensas, à semelhança do modo de produção feudal, porém incorporando apenas as pessoas, não mais os animais e os instrumentos de trabalho. Quando a valorização quantitativa da força de trabalho passou a dar lugar à valorização qualitativa, determinada pelo processo de transformação das forças produtivas decorrente da industrialização/ urbanização, as famílias foram se tornando menores, nucleares e aglutinadas em torno de interesses ideológicos de ascensão social. (HARRIS, 1986)

Em ambos os casos, no entanto, a ideologia dominante na constituição da família foi predominantemente a ideologia patriarcal, fundamentada na valorização do homem como sujeito social de poder máximo no grupo familiar, responsável pela subsistência através dos ganhos referentes ao trabalho público. A mulher, além das função bio-histórica de reprodução dos corpos, foi adicionada a função de reprodução e manutenção da força de trabalho, principalmente através do trabalho doméstico, característico do âmbito privado. (FONSECA, 1996)

Tanto a interpretação hegemônica (positivista/ funcionalista) como a não hegemônica (marxista) da divisão sexual do trabalho no modo de produção capitalista, no entanto, consideram o trabalho doméstico (predominantemente feminino) não produtivo e relacionado às funções clássicas e naturais da mulher, naturalização essa que tem se constituído no principal obstáculo à superação da situação social de subalternidade feminina, tanto nas sociedades capitalistas como nas socialistas. (FONSECA, 1996)

Como grupo social, a família pertence a diferentes estratos e classes, dadas suas diferenças culturais e a sua inserção no sistema produtivo. Essa é a razão pela qual falamos famílias, histórica e socialmente situadas, e não família no sentido universal. De todos esses recortes, nas sociedades onde ainda se verificam as grandes desigualdades sociais [como é o caso das sociedades industriais contemporâneas] o recorte primeiro e preponderante tem sido o das classes sociais e seus grupos sociais correspondentes - frações de classes. Em termos gerais, a classe social da família é dada pela inserção no sistema produtivo do membro da familia economicamente responsável pela totalidade ou ao menos pela maior parte de sua manutenção. Assim, pode ocorrer, numa mesma família, a convivência de pessoas que individualmente estão situadas em classes sociais distintas.

Em pesquisas realizadas na Grande São Paulo (SP), FONSECA (1990), BERTOLOZZI (1991), GRECO (1995) e BARRIENTOS (1998) buscaram diferentes formas de verificar a inserção social da familia a partir de seus componentes: o chefe indicado pela entrevistada, a própria entrevistada e de ambos. Uma análise transversal desses estudos permite concluir que, apesar de algumas distinções de classe social dentre seus membros, as famílias estudadas inseriam-se em 
classes sociais consideradas subalternas no sistema produtivo, mesmo porque os estudos foram realizados junto à população que freqüentava as unidades públicas de saúde. Não houve, no caso desses estudos, famílias de composição de classes tão díspares, ou seja, cujos membros pertenciam a extremos da classificação social, por exemplo, burguesia e proletariado.

Em tais sociedades, na lógica da manutenção do modo de produção vigente, o Estado, com o seu aparato jurídico-político-ideológico, perpetua as distinções entre as classes socais, quer no âmbito da produção, quer no da reprodução social. Assim, em geral, cada familia consegue reproduzir sujeitos sociais da sua própria classe, ou de classe imediatamente inferior, com tendência clara ao empobrecimento ou ao rebaixamento de classe ao longo das gerações.

Ao contrário, nas sociedades onde o Estado responsabiliza-se pela maior parte da formação da força de trabalho, há uma certa possibilidade de eqüidade na qualificação dos trabalhadores. Não se pode negar que um sistema escolar qualificado e acessivel a todos garante certa possibilidade de consecução dessa eqüidade. Contrariamente, os valores correntes em nossa sociedade outorgam a cada família a responsabilidade financeira e moral de qualificação da sua prole, responsabilizando-a também pelo ônus gerado pelas dificuldades advindas desse processo.

O papel das instituições públicas como as de saúde, no nosso modo de entender, é justamente buscar esta eqüidade ou a diminuição das desigualdades, privilegiando o acesso das famílias, especialmente das classes sociais menos favorecidas, às formas qualitativamente mais elevadas de vida e trabalho. Portanto, ao constituir um setor dentro de um serviço público, deve privilegiar a população com maiores riscos sociais de adoecer e morrer $\mathrm{e}$ com menores potencialidades para o enfrentamento de tais riscos.

\section{REVISITANDO A VISITA DOMICILIÁRIA}

No conjunto da produção de serviços de saúde coletiva, a Visita Domiciliária (VD) tem sido um dos instrumentos historicamente utilizados no âmbito da intervenção de enfermagem de saúde pública, preferentemente focalizando a família como alvo de atenção.

Integrando a prática de enfermagem de saúde pública, à semelhança de outras práticas da enfermagem brasileira, a VD teve origem nos modelos teórico-práticos advindos da sociedade norte-americana, vigentes na primeira metade deste século, como resultado das exigências sociais de afirmação da categoria profissional enfermeira de nivel universitário. A partir daí, tanto nos Estados Unidos como no Brasil - e na América Latina como um todo, que recebeu igualmente a influência norte-americana - a visita domiciliária foi adquirindo importância tal na produção daqueles serviços que deu origem a categorias ocupacionais especificamente preparadas para desempenhar tal procedimento. No Brasil, o visitados sanitário foi, durante quase três décadas, o profissional responsável pela atenção de enfermagem no domicílio tendo como alvo principal os clientes portadores de doenças transmissiveis e do grupo materno-infantil. (NOGUEIRA et al, 1977)

Da década de 70 em diante, as mudanças nas políticas de saúde, privilegiando a alocação de recursos financeiros e humanos para a assistência intra-hospitalar, provocaram um esvaziamento quantitativo e qualitativo das ações ditas de enfermagem de saúde pública, incluindose nelas a Visita Domiciliária. Contribuíram para essa situação, além da expansão das indústrias de equipamentos hospitalares e de medicamentos que respondem à tecnologia de ponta do setor, os ditames da ditadura militar brasileira sob o entendimento de que as ações de desenvolvimento de comunidade, realizadas historicamente pelos agentes de Saúde Pública, eram subversivas e contra a ordem social estabelecida e por isso mesmo sujeitas à intensa repressão. Assim, a gradativa transformação do modelo assistencial de higienista/ preventivista para o modelo dual curativista/ preventivista . acarretou a descaracterização das práticas de prevenção, dentre elas, a Visita Domiciliária.

Neste período, a VD foi considerada uma atividade fracionária, cumprindo uma normatização dentro da corrente funcionalpositivista, hegemônica.

Numa perspectiva mais totalizante, no marco da saúde coletiva, a VD configura-se de forma distinta. A antevisão de uma qualidade diferenciada das relações dialéticas família/saúde/ Estado, constitui a Finalidade do processo de trabalho de intervenção práxica de enfermagem em saúde coletiva no foco familial. Para que o processo se realize é necessário decodificar os Meios $e$ Instrumentos para a transformação do Objeto e, dentre eles, um dos Instrumentos historicamente utilizados tem sido a Visita Domiciliária.

Assim, a visita domiciliária pode ser redefinida como um instrumento no conjunto dos instrumentos (técnicas, procedimentos e saberes) da enfermagem em saúde coletiva, utilizado para intervenção no processo saúde-doença familial, 
realizada no local de moradia, e não de trabalho ou estudo. No dizer de BERTOLOZZI (1987), faz parte do "conjunto geral da assistência à saúde, que contribui para a dinamização da sistemática de ações integrantes dela. Enquanto área de atuação, constitui uma das atividades próprias da enfermagem, numa abordagem ampla que tem a finalidade de estender as ações de saúde à população, dentro de um contexto social".

\subsection{Algumas idéias equivocadas sobre a Visita Domiciliária}

A descaracterização da Visita Domiciliária como modalidade de atenção à família referida anteriormente, tem levado a algumas idéias equivocadas em relação a essa modalidade assistencial. Para evidenciar tais equívocos, discutiremos algumas idéias mais comumente expressas, quando se trata da VD, a começar pela própria designação.

\section{a)Visita domiciliar ou visita domiciliária?}

O vocábulo exato para designar esse procedimento é Visita Domiciliária porque, segundo FERREIRA (1986), o DOMICILIAR é um verbo transitivo direto. Significa dar domicílio a; recolher em domicílio; fixar residência ou fixar domicílio, enquanto que o DOMICILIÁRIO é um adjetivo relativo a domicílio, feito no domicílio e cujo feminino é domiciliária.

\section{b) Toda ida do técnico de saúde no domicilio é considerada visita domiciliária}

Essa idéia é equivocada porque para ser considerada Visita Domiciliária, a presença do técnico no domicílio deve seguir princípios e técnicas coerentes com o arcabouço teórico de sustentação da assistência de enfermagem no domicílio e não apenas a execução de um procedimento isolado como convocação de faltosos, por exemplo.

\section{c) Qualquer trabalhador do sistema de saúde encontra-se, atualmente, habilitado para realizar visitas domiciliárias, sem a necessidade de preparo especifico.}

Essa é outra idéia falsa pois o preparo para Visita Domiciliária envolve um conjunto de teorias e de procedimentos que tem sido objeto específico da formação de trabalhadores de algumas categorias da enfermagem e não de todos os trabalhadores da saúde ou mesmo da enfermagem.

d) A visita domiciliária é um procedimento caro e o setor saúde não tem recursos para incorporá-la nas suas práticas.
Trata-se aqui da relação custo/ beneficio da intervenção em enfermagem em saúde coletiva, contextualizada na finalidade da intervenção. Tal como qualquer outro procedimento, a VD não será considerada de alto custo $\boldsymbol{e}$ inviável se a sua finalidade for transformar o perfil de saúde-doença da população e não apenas lidar com queixas pontuais e específicas através de medidas igualmente pontuais e especificas, nem sempre eficazes. O item que requer maior custo comparativo é o do tempo dispendido para a realização da atividade, uma vez que as distâncias entre o domicílio e a Unidade de Saúde são relativamente extensas, principalmente se considerarmos a Cidade de São Paulo.

e) Se a população de uma dada área de abrangência tivesse $o$ hábito de recorrer às unidades básicas de saúde, a visita domiciliária seria dispensável.

As vantagens da Visita Domiciliária como modalidade assistencial são inúmeras, especialmente nos casos em que é necessária uma maior aproximação do técnico, representando o sistema de saúde, com a realidade de vida e saúde da família. Isso faz com que ela seja insubstituivel pelos procedimentos executados no interior da unidade de saúde, contexto em que as desigualdades sociais que constituem o grande determinante das condições de saúde-doença muitas vezes são de pouca visibilidade, impossibilitando sua apreensão pelos técnicos responsáveis pela atenção à saúde das famílias.

\subsection{Família e Visita Domiciliária}

$\mathrm{Na}$ totalidade da produção de serviços em saúde coletiva, a finalidade da atenção à saúde no domicílio refere-se à intervenção práxica no processo saúde-doença da família, quer destacando seus membros constituintes, quer enfocando a família na sua totalidade. Esse é o Objeto do Processo de Trabalho em tela.

Consideradas as finalidades e as prioridades, o setor de assistência à família deve ser organizado de tal forma a contemplar:

a) a intervenção nos perfis epidemiológicos das familias contidas na área de abrangência de uma dada unidade assistencial. Portanto, deve ser precedida por um estudo para determinar tal perfil e as necessidades de saúde dele decorrentes. Diferentemente dos estudos de perfis de morbimortalidade dos contingentes populacionais, quando se traça um perfil epidemiológico das famílias, há que considerar a dinâmica (interna/ externa) de constituição dos grupos familiares e as suas estratégias de sobrevivência e superação 
das dificuldades. Essa é uma das razões pelas quais é fundamental a qualificação específica dos trabalhadores de saúde para lidar com o processo saúde-doença das famílias.

b) a expansão da consciência crítica acerca das funções sociais da família na sociedade, ou seja, a função econômica, a ideológica e a de reprodução da força de trabalho (ARIÉS, 1986). Esta expansão da consciência, além da compreensão crítica das razões de outorga destes papéis, inclui o repensar sobre a articulação Estado/Família.

A VD é realizada recorrendo-se a três formas de abordagens: a entrevista, a observação sistematizada e a intervenção orientada/ participativa.

A entrevista é uma conversa dirigida por um roteiro - minucioso, contendo questões detalhadas ou conduzida por questões orientadoras, originadas das categorias interventivas ${ }^{1}$ - e que tem a finalidade de obter dados de duas naturezas, de acordo com MINAYO (1996): a) os que se referem a fatos objetivos e vivências concretas da realidade; b) os que se referem ao nivel mais profundo da realidade - os subjetivos - tais como atitudes, valores, sentimentos e opiniões. Segundo essa autora, "o que torna a entrevista instrumento privilegiado de coleta de informações [...] é a possibilidade de a fala ser reveladora de condições estruturais, de sistema de valores, normas e símbolos (sendo ela mesma um deles) e ao mesmo tempo ter a magia de transmitir, através de um porta-voz, as representações de grupos determinados, em condições históricas, sócioeconômicas e culturais específicas."

Explica BAKHTIN (1992) que "a palavra é a arena onde se confrontam os valores sociais contraditórios" e por meio da "comunicação verbal - que é inseparável de outras formas de comunicação - as pessoas 'refletem e refratam' conflitos e contradições próprias do sistema de dominação, onde a resistência está dialeticamente relacionada com a submissão" (MINAYO, 1996). A premissa básica da entrevista, diz a autora, é a situação de interação, não sendo uma simples coleta de dados, pois as informações advindas dos sujeitos entrevistados podem ser profundamente afetadas pela natureza de suas relações com o entrevistador.

Certamente, nessa situação de interação há uma evidente troca desigual entre os sujeitos em relação, pois a VD faz parte de uma totalidade permeada por desigualdades na divisão social do trabalho na sociedade em que vivemos.
A Observação é a outra forma de abordagem a que se recorre na VD e tem sua origem na antropologia de Malinowski, que teve continuidade na Escola de Sociologia de Chicago (HAGUETTE, 1987). Trata-se de um "compartilhar consciente e sistemático, conforme as circunstâncias permitam, nas atividades de vida e eventualmente, nos interesses e afetos de um grupo de pessoas" (Kluckholn, 1940 apud. HAGUETTE, 1987). É um processo no qual "a presença do observador é mantida para fins de investigação científica [e de intervenção no processo saúde-doença]. O observador está face a face com os observados" (HAGUETTE, 1987) participando do cotidiano da reprodução social no domicílio, tornando-se circunstancialmente parte desse contexto, modificando e sendo modificado na interação. Assim, a observação consiste na incorporação do sujeito observador ao processo de vida da população que investiga [e intervém], subordinada a um projeto estratégico, e no registro de um diário de observações (BREILH, 1995 trad. nossa).

A Intervenção orientada/participativa segue os preceitos e pressupostos da Metodologia de Intervenção Práxica da Enfermagem em Saúde Coletiva no processo de trabalho assistir, tendo como foco central a família na dimensão singular da realidade objetiva. (EGRY, 1996)

Assim, a Intervenção orientada/participativa refere-se à intervenção direta nos processos específicos de adoecer e morrer das famílias e dos indivíduos que as compõem e nas potencialidades de saúde verificadas no seu modo específico de viver. Na Intervenção, os conhecimentos condutores dessa internalidade devem ser expostos, relevándo os que têm a focalização no momento clínico (nexo biopsíquico), interseccionados por teorias de suporte e intervenção na dinâmica da família, e pautadas nos princípios da participação, definição de horizontes, responsabilidade compartilhada e construção conjunta na intervenção no processo saúde-doença da família. (EGRY, 1996)

\section{REDESCOBRINDO A VISITA DOMI- CILIÁRIA COMO MODALIDADE ASSIS- TENCIAL DE ENFERMAGEM EM SAÚDE COLETIVA, TENDO A FAMÍLIA COMO OBJETO DE ATENÇÃO, NO CONTEXTO DO PSF.}

Existe hoje uma tendência à recolocação da prática assistencial de saúde denominada "médico

Categorias interventivas correspondem aos eixos temáticos que deverão ser abordados na condução da Teoria de Intervenção Práxica da Enfermagem em Saúde Coletiva. A esse respeito ler EGRY, E.Y. Saúde Coletiva: construindo um novo método em enfermagem São Paulo, Ícone, 1996. 
de família" sob várias argumentações: expansão de cobertura dos serviços de saúde; "humanização" do atendimento; redução de custos com internações desnecessárias; aumento de adesão da população ao sistema de saúde, principalmente no que se refere a tratamentos instituídos, entre outras. (MISOCZKY, 1994)

Ressalte-se que o principal custo de uma internação é o social, tanto do ponto de vista da família que tem rompida sua dinâmica familiar e estrangulado o ingresso de recursos para sua subsistência, como da própria sociedade que simultaneamente subtrai o trabalhador do seu trabalho (fisica ou emocionalmente). Acresce-se a isso o gasto com a própria internação, considerados todos os riscos nela embutidos (iatrogenia, não resolução do problema, etc).

Supostamente, a atuação do médico de família e a ação dos serviços de saúde extra-hospitalares reduziriam estes custos com a correspondente resolutividade da problemática de saúde da família/ indivíduo. No entanto, dado o modelo assistencial vigente hoje no Brasil - biologicista e funcionalista que visa a resolução imediatista das queixas, a adoção desta prática assistencial, concretamente, levará à simplificação e ao barateamento da assistência, com diminuição do custo direto arcado pelo setor saúde. Os demais custos serão de responsabilidade da família, reiterando a visão de que a ela compete arcar com a manutenção e reprodução social. Na verdade, mais uma vez, o Estado eximir-se-á da responsabilidade de intervir na saúde como um bem social, numa resposta direta da ideologia neoliberal vigente na área da saúde. (TEIXEIRA, 1992)

A implantação do Sistema Único de Saúde tem sido vista como a grande possibilidade de ultrapassar essas contradições, especialmente pela mudança no paradigma que o sustenta e nas práticas dele decorrentes, dados os seus princípios (BRASIL, 1990). É inegável que, apesar dos descompassos na municipalização dos serviços de saúde, o novo modelo organizativo de atenção à saúde vem aportando avanços consideráveis, principalmente no tocante ao controle social e um maior controle da assistência hospitalar, através da Autorização de Internação Hospitalar - AIH (MENDES, 1996).

Nesse cenário é que surge, como proposição do Ministério da Saúde, o Programa Saúde da Família - PSF, proposta estratégica de reestruturação do modelo assistencial dominante que, em tese, integra o Sistema Local de Saúde SILOS, constituindo-se em Unidade Prestadora de Serviços. Muda-se, assim, o objeto de atenção, que passa a ser a família, a partir do espaço em que ela vive, ou seja, o domicílio. A inserção da família como foco, de atuação na política de saúde, como propõe o PSF, entende a família como sujeito do processo assistencial de saúde, definindo o domicílio como um espaço social e histórico onde são construídas as relações intra e extra familiares e no qual ocorrem as lutas pela sobrevivência, pela produção e reprodução. (FUNDAÇÃO NACIONAL DE SAÚDE, 1994; BRASIL, 1996)

Nessa perspectiva, a atenção à saúde no domicílio através da Visita Domiciliária e as demais práticas extra-muros subordinadas ao novo paradigma teriam especial sentido e lugar como instrumentos imprescindiveis para a intervenção no processo saúde-doença da população. Ao vislumbrar a renovada possibilidade, a enfermagem poderia constituir prática social de excelência dado o seu lastro histórico de prática e produção de saber neste campo. Do conjunto dos trabalhadores de saúde em geral e especialmente da enfermagem em saúde coletiva, a/o enfermeira/o é o profissional que deveria estar melhor instrumentalizada diante deste novo objeto.

\section{4 À GUISA DE SÍNTESE}

Historicamente, a Visita Domiciliária tem sido um instrumento de atenção de enfermagem à família. Entretanto, pode ser revisitada como uma modalidade de atenção quando se destaca a família como Objeto de intervenção da enfermagem, tornando-se uma possibilidade focal da Teoria de Intervenção Práxica da Enfermagem em Saúde Coletiva (TIPESC), descrita por EGRY, em 1994. Nessa perspectiva, ela deve estar ancorada nos pressupostos teórico-conceituais dá TIPESC, desdobrando-se operacionalmente de acordo com as etapas de: captação da realidade objetiva; interpretação da realidade objetiva; construção do projeto de intervenção na realidade objetiva; intervenção na realidade objetiva; e reinterpretação da realidade objetiva. (EGRY,1996)

É oportuno para a enfermagem em saúde coletiva utilizar o instrumental da Visita Domiciliária para executar ações pertinentes ao Programa de Saúde da Família - PSF. É preciso, no entanto, que se considerem as questões postas neste ensaio para uma prática crítica e renovadora, buscando compreender as raízes teórico-filosóficas nas quais estão apoiadas as categorias conceituais que aproximam do Objeto.

Tal perspectiva dar-se-á quando a prática for competentemente exercida pelos atuais trabalhadores da área da enfermagem em saúde coletiva, ao mesmo tempo em que as instituições formadoras valorizarem e inserirem nos seus programas de estudo os saberes necessários para esta prática. 
Nenhuma transformação dar-se-á isoladamente sem o correspondente movimento por parte dos trabalhadores reivindicando a assunção da tarefa de assistir em saúde com esta visualização, movimento este simultaneamente produzido na academia pela formação diferenciada da/o enfermeira/o no novo paradigma de intervenção.

\section{REFERENCIAS BIBLIOGRÁFICAS}

ALmeidA, A.M. de (org) Pensando a familia no Brasil: da colônia à modernidade. Rio de Janeiro, Espaço e Tempo, 1987.

ARIES, F. História social da criança e da familia. 2 ed. Rio de Janeiro, Guanabara, 1986.

BAKHTIN, M. Marxismo e filosofia da linguagem. São Paulo, Hucitec, 1992.

BARRIENTOS, D.M.S. Mulher \& saúde: buscando uma visão generificada na percepção das usuárias acerca do exame ginecológico". São Paulo, 1998. Dissertação (Mestrado) - Escola de Enfermagem, Universidade de São Paulo.

BERTOLOZZI, M.R. Estudo da visita domiciliária enquanto forma de atenção à saúde. São Paulo, 1987. 71p. (Relatório de Pesquisa) Escola de Enfermagem da Universidade de São Paulo.

BERTOLOZZI, M.R. Pacientes com tuberculose pulmonar no Municipio de Taboão da Serra: perfil e representações sobre a assistência prestada nas unidades básicas de saúde. São Paulo, 1991. 213p. Dissertação (Mestrado) - Faculdade de Saúde Pública, Universidade de São Paulo.

BRASIL, Leis etc. Lei n. 8080 de 19 de setembro de 1990. Dispõe sobre as condições para a promoção, proteção e recuperação da saúde, a organização e o funcionamento dos serviços correspondentes e dá outras providências. Diário Oficial da União. Brasília, 20 set. 1990. Seção 1, p. 18055-9

BRASIL, Ministério da Saúde. Secretaria de Assistência. Departamento de Assistência e Promoção à Saúde. Coordenação de Saúde da Comunidade. Saúde da familia: estratégia de organização dos serviços de saúde. Brasilia, 1996. (Documento preliminar)

BREILH, J. Nuevos conceptos y técnicas de investigación: quía pedagógica para un taller de metodología. 2 a ed. Quito, CEAS, 1995.

EGRY, E.Y. Saúde coletiva: construindo um novo método de enfermagem. São Paulo, Ícone, 1996.

EGRY, E.Y. et al. Assistência de enfermagem em saúde coletiva: entendendo o processo para a aplicação de um instrumento transformador da prática e da teoria. R.Bras.Enf., v.47, n.3, p.28'7-94, 1994.

ENGELS, F. A origem da familia, da propriedade privada e do Estado. 9 a ed. Rio de Janeiro, Civilização Brasileira, 1984.

\section{Agradecimento}

À Professora Doutora Maria Amélia de Campos Oliveira, docente do Departamento de Enfermagem em Saúde Coletiva da Escola de Enfermagem da Universidade de São Paulo, pela colaboração inestimável na revisão técnica do texto.

FERREIRA, A.B.H. Novo Dicionário da Lingua Portuguesa. $2^{a}$ Ed. Rio de Janeiro, Nova Fronteira, 1986. p.607

FONSECA, R.M.G.S. da Mulher, reprodução biológica e classe social: a compreensão do nexo coesivo através do estudo dialético do perfil reprodutivo biológico de mulheres atendidas nas Unidades Básicas de Saúde. São Paulo, 1990. 356p. Tese (Doutorado) - Escola de Enfermagem, Universidade de São Paulo.

FONSECA, R.M.G.S. da Mulheres e enfermagem: uma construção generificada do saber. São Paulo, 1996. 180p. Tese (Livre-docência). Escola de Enfermagem da Universidade de São Paulo.

FUNDAÇÃO NACIONAL DE SAÚDE. Departamento de Operações. Coordenação de saúde da comunidade. Programa de saúde da família. Brasília, Ministério da Saúde, 1994.

GONÇALVES, R.B.M. O processo de trabalho em saúde. São Paulo, Departamento de Medicina Preventiva da Faculdade de Medicina da Universidade de São Paulo. 1988. / mimeografado/

GRECO, R.M. Representações de mulheres acerca de sua saúde a partir da percepção do exame ginecológico. São Paulo, 1955. (Relatório de Pesquisa), Escola de Enfermagem, Universidade de São Paulo.

HAGUETTE, T.M.F. Metodologias qualitativas na sociologia. Petrópolis, Vozes, 1987.

HARRIS, CC. Familia y sociedad industrial. Barcelona, Peninsula, 1986.

MENDES, E.V. Uma agenda para a saúde. São Paulo, HUCITEC, 1996.

MINAYO, M.C. de S. O desafio do conhecimento: pesquisa qualitativa em saúde. 4 a ed. São Paulo-Rio de Janeiro, HUCITEC-ABRASCO, 1996.

MISOCZKY, M.C. A medicina de familia: os ouvidos do príncipe e os compromissos com o SUS. Saúde deb., n.42, p.40-4, 1994.

NOGUEIRA, M.J.C. et al. A visita domiciliária como método de assistência de enfermagem à família. Rev.Esc.Enf.USP, v.11, n.1, p.28-50, 1977.

TEIXEIRA, S.F. Politicas de saúde no Brasil: situação atual e desafios estratégicos. Saúde deb., n.35, p.4-10, 1992. 